\title{
Investigating Genetic Mutations in a Large Cohort of Iranian Patients with Congenital Hyperinsulinism
}

\author{
(D) Maryam Razzaghy-Azar1,2, (iD Saeedeh Saeedi1,3, (D) Sepideh Borhan Dayani ${ }^{1}$, (D) Samaneh Enayati1 , (D) Farzaneh Abbasi4, \\ (D) Somayyeh Hashemian5, (D) Peyman Eshraghi5, (D) Siroos Karimdadi5, (D) Parisa Tajdini4, (D) Rahim Vakili5, (D) Mahsa M. Amoli1, \\ (D) Hanieh Yaghootkar6 \\ ${ }^{1}$ Tehran University of Medical Sciences, Endocrinology and Metabolism Molecular-Cellular Sciences Institute, Metabolic Disorders Research \\ Centre, Tehran, Iran \\ 2Iran University of Medical Sciences, H. Aliasghar Hospital, Tehran, Iran \\ ${ }^{3}$ Tehran University of Medical Sciences, Endocrinology and Metabolism Clinical Sciences Institute, Endocrinology and Metabolism Research \\ Center, Tehran, Iran \\ 4 Tehran University of Medical Sciences, Children's Medical Center Hospital, Growth and Development Research Center, Tehran, Iran \\ 5 Mashhad University of Medical Sciences, Faculty of Medicine, Akbar Hospital, Department of Pediatric Diseases, Mashhad, Iran \\ 6University of Exeter, College of Medicine and Health, Genetics of Complex Traits, London; University of Westminster, School of Life Sciences, \\ Research Centre for Optimal Health, London, England; Luleå University of Technology, Department of Health Sciences, Division of Medical \\ Sciences, Luleå, Sweden
}

\section{What is already known on this topic?}

It is well known that congenital hyperinsulinism $(\mathrm{CHI})$ is the most frequent cause of severe and persistent hypoglycaemia in the neonatal period, infancy, and childhood. To date, mutations in at least nine different genes have been reported to cause CHI: $A B C C 8, K C N J 11$, GLUD1, GCK, HADH, HNF4A, SLC16A1, HNF1A and UCP2. Data are mainly limited to European populations while the occurrence of the pathogenic mutations underlying $\mathrm{CHI}$ are higher in consanguineous families which are more prevalent in Asian societies.

\section{What this study adds?}

We report the frequency of causal gene mutations in a cohort of Iranian children with a diagnosis of CHI and add five novel mutations. Based on our findings we recommend screening of $H A D H$ gene variants in all patients with diazoxide-responsive $\mathrm{CHI}$ if there is no access to targeted next generation sequencing.

\begin{abstract}
Objective: Congenital hyperinsulinism $(\mathrm{CHI})$ is the most frequent cause of severe and persistent hypoglycaemia from birth. Understanding the pathophysiology and genetic defects behind hyperinsulinism and its complications provides clues to timely diagnosis and management. The aim of this study was to evaluate the underlying genetic aetiology of a specific Iranian pediatric cohort with $\mathrm{CHI}$. Methods: A total of 44 unrelated children, 20 girls and 24 boys, with an initial diagnosis or history of CHI from all regions of Iran were recruited between 2016 and 2019. Targeted next generation sequencing (tNGS) was performed for the genes found in about half of CHI patients.

Results: Mutations were identified in 24 cases (55\%). Patients with a confirmed genetic cause were mainly diagnosed below age of one year old $(p=0.01)$, had fewer other syndromic features, excluding seizure, $(p=0.03)$, were less diazoxide responsive $(p=0.04)$ and were more diazoxide unresponsive leading to pancreatectomy $(\mathrm{p}=0.007)$ compared to those with no identified mutations. Among 24 patients with identified genetic mutations, 17 (71\%) had a mutation in $A B C C 8,3(12 \%)$ in KCNJ11, 3 (12\%) in HADH, and 1 patient had a mutation in $K M T 2 D$. These included five novel mutations in $A B C C 8, K C N J 11$, and KMT2D.
\end{abstract}

Address for Correspondence: Hanieh Yaghootkar MD, University of Exeter, College of Medicine and Health, Genetics of Complex Traits, London, England

E-mail: h.yaghootkar@exeter.ac.uk ORCID: orcid.org/0000-0001-9672-9477

Address for Correspondence: Mahsa M. Amoli MD, Tehran University of Medical Sciences, Endocrinology and Metabolism Molecular-Cellular Sciences Institute, Metabolic Disorders Research Centre, Tehran, Iran

E-mail: amolimm@tums.ac.ir ORCID: orcid.org/0000-0002-9168-9223

${ }^{\circ}$ Copyright 2022 by Turkish Pediatric Endocrinology and Diabetes Society

The Journal of Clinical Research in Pediatric Endocrinology published by Galenos Publishing House.
Conflict of interest: None declared Received: 11.04 .2021 Accepted: 29.11.2021 
Conclusion: This is the biggest genetic study of $\mathrm{CHI}$ in Iran. A high frequency of recessive forms of $\mathrm{CHI}$, especially $\mathrm{HADH}$ mutations, in our study could be due to a high rate of consanguineous marriage. We recommend tNGS to screen for all the $\mathrm{CHI}$ genes.

Keywords: Congenital hyperinsulinism, genetic mutations, diazoxide, targeted next generation sequencing

\section{Introduction}

Congenital hyperinsulinism $(\mathrm{CHI})$ is the most frequent cause of severe and persistent hypoglycaemia and the most common metabolic abnormality in the neonatal period, infancy, and childhood $(1,2)$. There is an unregulated secretion of insulin from pancreatic $\beta$-cells in the course of low blood glucose in CHI patients, leading to severe and persistent hypoglycaemia due to genetic defects $(3,4)$. CHI is rare but a very high incidence has been reported in isolated European populations and also communities with a high rate of consanguinity $(5,6,7)$. About $60 \%$ of infants with $\mathrm{CHI}$ develop hypoglycaemia during the first months of life. This condition typically goes through remission and flareup cycles due to hypoglycaemia. Age of onset is variable and symptoms can range from asymptomatic and mild to severe symptoms, including medically unresponsive hypoglycaemia $(5,6)$.

The clinical manifestations, histological subtypes and underlying molecular mechanisms of $\mathrm{CHI}$ are heterogeneous (4). Based on histological assessments, there are two major subtypes of $\mathrm{CHI}$ including diffuse and focal forms $(3,8)$. The differentiation between these two subtypes is important for clinical management. The diffuse form, where abnormality is in all pancreatic $\beta$-cells, is inherited in an autosomal recessive or dominant mode, most commonly due to mutations in $A B C C 8$ and $K C N J 11$. Recessive mutations in $A B C C 8 / K C N J 11$ are usually severe and require high concentrations of intravenous glucose to maintain normoglycemia while dominant mutations usually cause milder disease. The focal form is confined to a small region of the pancreas with sporadic inheritance. This subtype results from a heterozygous paternal mutation in $A B C C 8 / K C N J 11$ and somatic loss of maternal chromosome 11 p1 5 in the focal pancreatic lesion (9).

Understanding the pathophysiology and genetic defects behind hyperinsulinism and its complications has provided clues to diagnosis and management of the disease. Since $\mathrm{CHI}$ causes a set of complex and heterogenous metabolic complications, cases will have different clinical presentation with different age of onset and prognosis. The conservative treatment includes diazoxide as first choice. However, some children, mainly those with the recessive mutations in $A B C C 8 /$ $K C N J 11$, develop a form of disease unresponsive to medical therapy and so pancreatectomy is the only option $(3,10)$.
Since severe hypoglycaemia has a negative effect on neural system function, especially during the early years of life, early diagnosis and treatment are important. In recent decades there has been a substantial expansion in information of genetic defects leading to $\mathrm{CHI}$. To date, mutations in at least nine different genes have been reported to cause CHI: ABCC8, KCNJ11, GLUD1, GCK, HADH, HNF4A, SLC16A1, HNF1A and UCP2 $(4,9)$. These genes are involved in regulating insulin secretion from $\beta$-cells (4). Data about $\mathrm{CHI}$ are mainly limited to European populations. However, the occurrence of the pathogenic mutations underlying $\mathrm{CHI}$ is increased in consanguineous families compared with non-consanguineous families (4). Therefore, investigating the aetiologies of this disorder is even more momentous in Asian countries with highly consanguineous populations, including Iran.

The aim of this study was to assess genetic mutations underlying $\mathrm{CHI}$ by recruiting individuals diagnosed with CHI. All the genetic and clinical data was combined to provide an Iranian $\mathrm{CHI}$ database for patients and specialists. We also report the frequency of causal gene mutations and describe a number of novel mutations.

\section{Methods}

\section{Study Participants}

Unrelated participants diagnosed with $\mathrm{CHI}$ were recruited to the study. Patients were from all regions of Iran and who had been referred to two centres in Iran, Imam Reza Hospital, Mashhad, Iran and the Division of Endocrinology and Metabolism in the Department of Paediatrics at the Children's Medical Centre in Tehran, Iran (Table 1). Clinical information was supplied by the referring clinicians. Informed consent was obtained from parents on behalf of their children. Peripheral blood samples were collected from affected participants and their parents at the time of referral and used to perform genetic testing.

\section{Clinical Data}

$\mathrm{CHI}$ was defined as fasting hypoglycaemia [glucose $<50$ $\mathrm{mg} / \mathrm{dL}(2.8 \mathrm{mmol} / \mathrm{l})]$ occurring simultaneously with an inappropriately detectable plasma insulin $(>2.0 \mu \mathrm{U} / \mathrm{mL})(11)$. Paediatric subjects whose hyperinsulinemic hypoglycemia $(\mathrm{HH})$ did not remit after at least three months follow-up were eligible to be enrolled in this study. A detailed clinical 
and demographical history, along with EDTA blood sample from the affected individual, both parents and affected siblings, were obtained. In the clinical history, diazoxideresponsiveness was defined as the ability to achieve elevated intravenous glucose and maintain normoglycemia (12). Low birth weight was determined based on birth weight adjusted by the gestational age (13).

\section{Genetic Analysis}

The genetic testing and variant interpretation were performed by the Exeter Molecular Genetics Laboratory (Exeter, UK). Briefly, DNA was extracted using standard methods and the samples were analysed for coding and flanking intronic regions of the KCNJ11 (NM_000525.3) and ABCC8 (NM_001287174.1) genes by Sanger sequencing. If no mutation was found, targeted next generation sequencing (tNGS) (Agilent custom capture v5.3/Illumina NextSeq500) for the coding regions and exon/intron boundaries of the genes found in about half of CHI patients (ABCC8, KCNJ11, AKT2, GLUD1, GCK, GPC3, HADH, HNF4A, KDM6A, KMT2D, SLC16A1, CACNA1D, PMM2, TRMT10A and HNF1A) (14) was performed. This assay can also detect partial/whole gene deletions and duplications (15). For a patient with mosaicism in KMT2D, a confirmatory dosage analysis of exons 51-54 of the KMT2D genes (NM_003482.3) by Droplet Digital PCR using EvaGreen was performed.

Variants were classified according to the American College of Medical Genetics and Genomics and the Association for Molecular Pathology standards and guidelines for the interpretation of sequence variants (16). The frequencies of the identified variants were checked in GnomAD [>120 000 individuals (http://gnomad.broadinstitute. org)] and in human variant and mutation databases, such as ClinVar and Human Gene Mutation Database, as well as in the literature via PubMed and Google searches. The in silico tools SIFT, PolyPhen-2 and Align-GVGD were used to assess the pathogenicity of missense variant effects, and the prediction of variant effect on mRNA splicing was made using SpliceSiteFinder-like, MaxEntScan, GeneSplice, NNSPLICE and Human Splicing Finder. All in silico programs were accessed through the ALAMUT Visual software version 2.7.1 (Interactive Biosoftware, Rouen, France). Conservation of amino acids and nucleotides across multiple species was performed using the University of California Santa Cruz genome browser (http://genome. ucsc.edu).

\section{Ethical Considerations}

The study was approved by the Ethical Committee of the Endocrinology and Metabolism Research Institute (ethical code: IR.TUMS.EMRI.REC.1397.009, date: 18.07.2018). The consent form was signed by all participants, or in the case of minors, the consent form was signed by their parents or legal guardian. A signed, written consent form was separately obtained for genetic testing. All procedures performed in this study were in accordance with the ethical standards of the 1964 Helsinki Declaration and its later amendments or comparable ethical standards.

\section{Statistical Analysis}

We used the chi-square test to assess the differences between patients with confirmed genetic cause and those with no identified mutations groups.

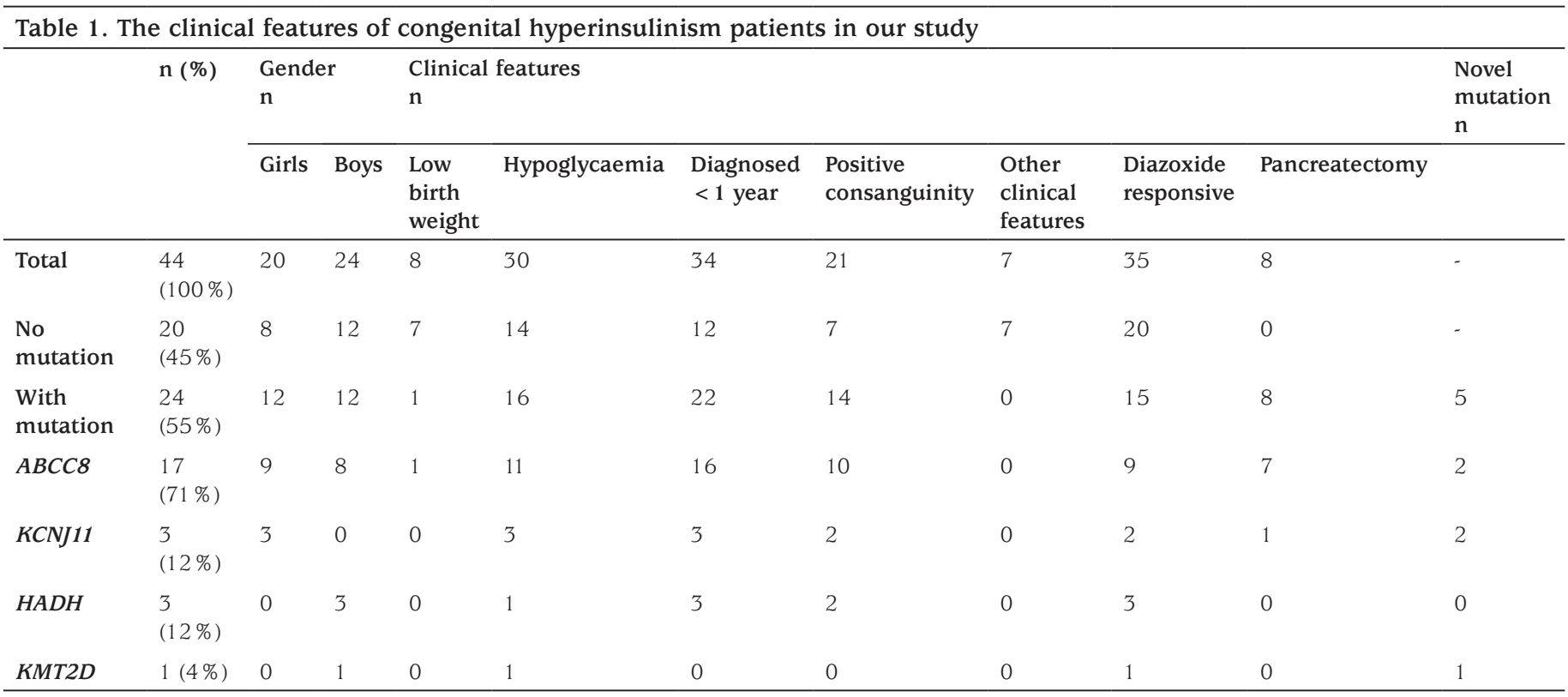




\section{Result}

\section{Patient Characteristics}

Forty-four unrelated children, 20 (45.45\%) girls, with an initial diagnosis or history of $\mathrm{CHI}$ from all regions of Iran, diagnosed between 2016 and 2019 were recruited. Of the 44, 21 children (48\%) came from consanguineous families (Table 1). Age of diagnosis varied but 36 $(81.8 \%)$ were diagnosed before their first birthday. Only two $(4.5 \%)$ patients had a positive family history of hypoglycaemia and $13(29.5 \%)$ had a family history of diabetes. Low birth weight was reported for 10 (22.7\%) patients. Insulin level ranged from 7.2 to $147 \mathrm{mU} / \mathrm{L}$ within our population and pancreatectomy had already been performed in eight (18.2\%). Other symptoms, including hypokalaemia, autism, renal failure, seizure, oesophageal atresia, and failure to thrive were observed in $14(31.8 \%)$. Nine out of 44 patients $(20.45 \%)$ were Diazoxideunresponsive including eight patients who had a history of pancreatectomy.

Disease causing mutations were identified in 24 cases $(55 \%)$. Patients with a confirmed genetic cause in any of the known genes, were mainly diagnosed below the age of one year old $(p=0.01)$, had fewer other syndromic features, excluding seizure $(p=0.03)$, were less diazoxide responsive $(p=0.04)$ and were more diazoxide unresponsive leading to pancreatectomy $(p=0.007)$ compared to those with no identified mutations. Birth weight, hypoglycaemia and consanguinity rate was similar between the two groups (Tables 1, 2, 3).

\section{Genetic Findings}

Among 24 patients with identified genetic mutations, 17 (71 \%) had a mutation in $A B C C 8,3$ (12\%) in KCNJ11, 3 (12\%) in $H A D H$, and one patient had a mutation in KMT2D (Table 1). These included five novel mutations in $A B C C 8, K C N J 11$, and KMT2D. Details of the mutations and the clinical features of the patients are described below and in Table 2 .

Patients with $A B C C 8$ mutations. A total of 17 probands, including eight males and nine females were found with mutations in $A B C C 8$ gene, of whom two patients were carrying novel mutations; a homozygous in-frame deletion (c4724-4732del) and a heterozygous missense de novo mutation (c.1109G > C; p.Arg370Thr). Both of these patients were diazoxide responsive. In total, five patients had heterozygous mutations, one compound heterozygous and 11 patients had homozygous mutations. Ten patients (59\%) were from consanguineous families. The median (interquartile range) birth weight was 3550 (3200-4200) g. Eight patients (47\%) were diazoxide unresponsive and had undergone pancreatectomy. Other clinical features included seizure in two (11.8\%) patients.

Patients with KCNJ11 mutations. All three patients were homozygous, including two with novel missense mutations (c.362T > G; p.Phe121 Cys and c.370T > A; p.Ser124Thr) who were both diazoxide responsive. Birth weight was between $3800 \mathrm{~g}$ and $4880 \mathrm{~g}$. The patient with c.287_288delinsTG mutation (p.Ala96Val) had a history of seizure, was diazoxide unresponsive and underwent pancreatectomy.

Patients with $H A D H$ mutations. Three cases were detected with $H A D H$ gene mutations, of whom one case was homozygous for a frameshift variant (c.617del; p.Lys206fs) and the other two were homozygous for a nonsense variant (c.706C > T; p.Arg236Ter). Two patients were from consanguineous families and had seizures. Birth weight ranged from $3250 \mathrm{~g}$ to $4800 \mathrm{~g}$. The response to diazoxide was good in all the patients.

Patient with KMT2D mutation. One patient was mosaic for a KMT2D partial gene deletion of exons 51-54. The level of mosaicism within his leukocyte DNA was estimated to be at least $20 \%$, consistent with a post-zygotic origin. Genetic testing in the parents indicated a de novo change. The patient was from a non-consanguineous family and was diagnosed with hyperinsulinism at the age of two years. Birth weight was $4500 \mathrm{~g}$ and the response to diazoxide was good. The patient had a history of seizure and did not have any facial dysmorphism.

\section{Diazoxide Responsiveness and Pancreatectomy}

Diazoxide unresponsiveness was seen in nine $(38 \%)$ of the patients with genetic mutations. These included eight patients (89\%) with mutations in $A B C C 8$ and one with KCNJ11 mutation. This figure means $45 \%$ of those with $\mathrm{K}_{\text {ATP }}$-channel mutations were diazoxide-unresponsive. Seven out of eight $(88 \%)$ patients who had had pancreatectomy had ABCC8 gene mutations and one had KCNJ11 mutation. Pathogenic mutation was invariably found in diazoxideunresponsive patients $(9 / 9 ; 100 \%)$, although more than half of cases in the diazoxide-responsive group $(20 / 35 ; 57 \%$ ) had no genetic variant identified in the genes investigated (Figure 1).

\section{Discussion}

We described the spectrum of genetic mutations in $\mathrm{CHI}$ in an Iranian population, as well as the frequency of each mutation and their related clinical features. Genetic mutations were found in $55 \%$ of our patients, consistent with previous studies which identified mutations in 12 out of 19 (63\%) patients in Turkey (10) or in only $47 \%$ (56 of 118) 


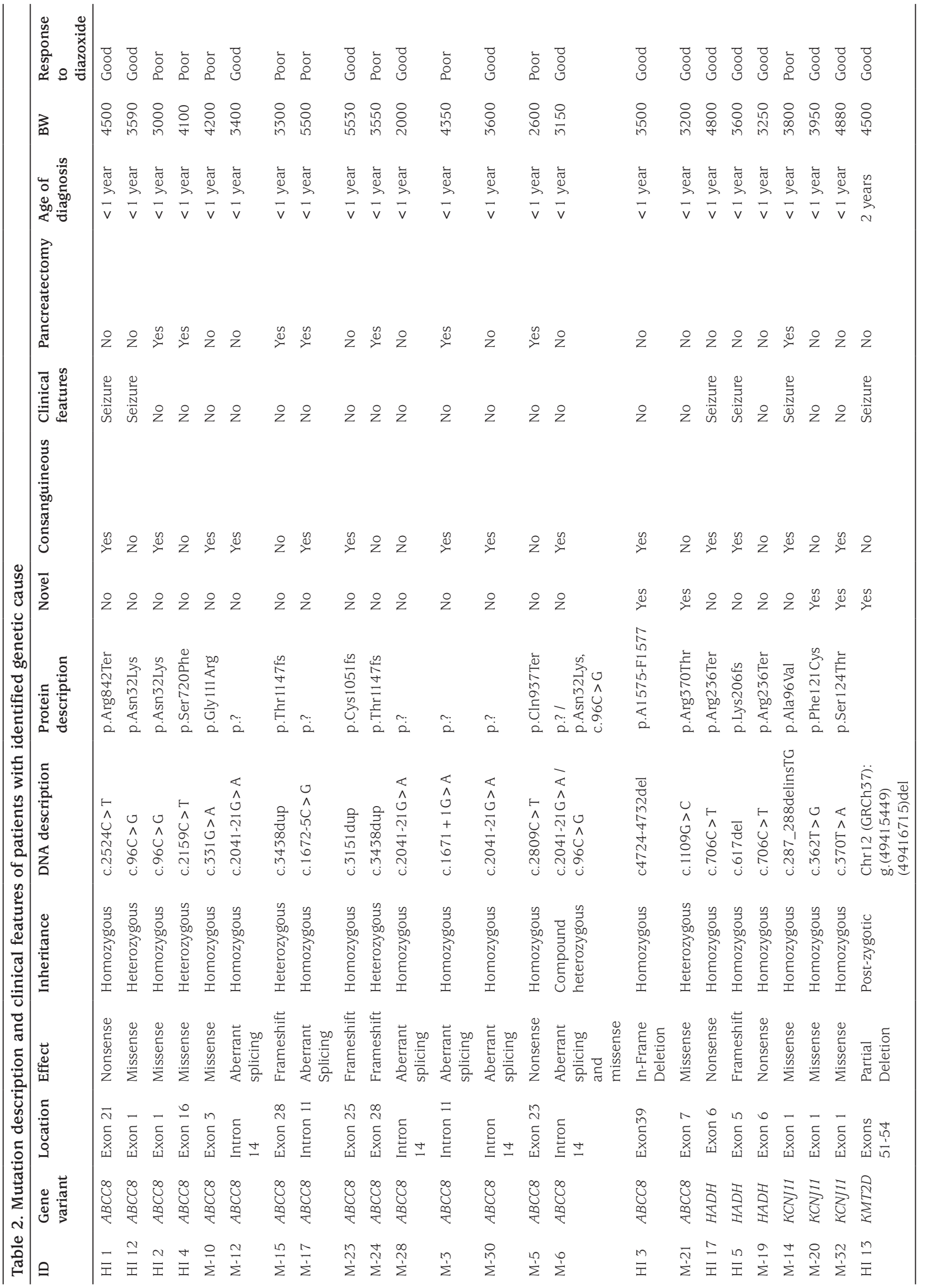


of the diazoxide-responsive cases in the US (17). This figure is lower than some studies, which could reflect differences in referral patterns and inclusion or exclusion criteria (18).

Consistent with previous studies $(17,19,20)$, mutations in $\mathrm{K}_{\text {ATP }}$-channel including SUR1 (ABCC8) and Kir6.2 (KCNJ11), accounted for $83 \%$ of all CHI-causing mutations in our study. Mutations in the $A B C C 8$ gene with $71 \%$ occurrence was the most frequent cause of $\mathrm{CHI}$ in our population. In addition, eleven participants were homozygous for a mutation in $A B C C 8$ which confirmed a diagnosis of autosomal recessive $\mathrm{CHI}$. One patient was homozygous for a novel, in-frame deletion in $A B C C 8$, which requires further investigation to determine its clinical significance.

The majority of recessive mutations in the $\mathrm{K}_{\text {ATP }}$-channel has been shown to lead to medically unresponsive $\mathrm{CHI}$
$(21,22)$, but in our study, six out of 11 patients with homozygous $A B C C 8$ mutations and two out of three patients with homozygous KCNJ11 mutations were diazoxide-responsive. Although Salomon-Estebanez et al (23) had suggested that this may be due to the reduction of severity of disease over time, it is not reasonably likely and may be due to variable criteria used to determine diazoxide responsiveness. In contrast, $A B C C 8$ and $K C N J 11$ heterozygous mutations were characterized by various presentations and treatment responses; three out of six $(50 \%)$ patients with heterozygous mutations were diazoxide-unresponsive which is in agreement with other studies (21). In our study, all heterozygous mutations were in the $A B C C 8$ gene, which may indicate a dominant pattern of inheritance for certain mutations in the $A B C C 8$ gene.

\begin{tabular}{|c|c|c|c|c|c|c|c|}
\hline ID & Genetic test & Consanguineous & Clinical features & Pancreatectomy & $\begin{array}{l}\text { Age of } \\
\text { diagnosis }\end{array}$ & BW & $\begin{array}{l}\text { Response to } \\
\text { diazoxide }\end{array}$ \\
\hline HI 11 & tNGS & No & No & No & 4 years & 3800 & Good \\
\hline HI 14 & $\mathrm{tNGS}$ & Yes & $\begin{array}{l}\text { Renal cyst, abnormal } \\
\text { internal genitalia }\end{array}$ & No & 13 months & NA & Good \\
\hline HI 6 & $\mathrm{tNGS}$ & Yes & $\begin{array}{l}\text { Hypocalcemia, autism, } \\
\text { renal failure, nephrectomy }\end{array}$ & No & 10 years & 3700 & Good \\
\hline M-1 & tNGS & No & No & No & 2 years & 1930 & NA \\
\hline $\mathrm{M}-11$ & tNGS & Yes & No & No & $\begin{array}{l}\text { Diagnosed } \\
<1 \text { year }\end{array}$ & 3200 & Good \\
\hline M-18 & tNGS & Yes & No & No & After birth & 3250 & Good \\
\hline $\mathrm{M}-2$ & tNGS & No & No & No & 4.5 months & 3300 & Good \\
\hline M-25 & tNGS & No & No & No & 2 years & 3500 & Good \\
\hline $\mathrm{M}-27$ & tNGS & Yes & $\begin{array}{l}\text { Precocious puberty, } \\
\text { hypothyroidism }\end{array}$ & No & 4 years & 3100 & Good \\
\hline M-9 & tNGS & No & GI obstruction & No & 7.5 years & 1890 & Good \\
\hline HI 10 & $A B C C 8 \& K C N J 11$ & Yes & No & No & $\begin{array}{l}\text { Diagnosed } \\
<1 \text { year }\end{array}$ & 3500 & Good \\
\hline HI 9 & $A B C C 8 \&$ \& KCNJ11 & No & Esophageal atresia & No & $\begin{array}{l}\text { Diagnosed } \\
<1 \text { year }\end{array}$ & 1069 & Good \\
\hline M-13 & $A B C C 8 \&$ \&CNJ11 & No & No & No & $\begin{array}{l}\text { Diagnosed } \\
<1 \text { year }\end{array}$ & 3050 & Good \\
\hline M-16 & $A B C C 8 \& K C N J 11$ & Yes & Macroglossia & & $\begin{array}{l}\text { Diagnosed } \\
<1 \text { year }\end{array}$ & 4200 & Good \\
\hline $\mathrm{M}-22$ & $A B C C 8 \&$ \&CNJ11 & No & No & No & 2 years & 1700 & Good \\
\hline M-26 & $A B C C 8 \& K C N J 11$ & No & No & No & $\begin{array}{l}\text { Diagnosed } \\
<1 \text { year }\end{array}$ & 3970 & NA \\
\hline M-29 & $A B C C 8 \& K C N J 11$ & No & No & No & $\begin{array}{l}\text { Diagnosed } \\
<1 \text { year }\end{array}$ & 1600 & Good \\
\hline M-31 & $A B C C 8 \& K C N J 11$ & No & No & No & $\begin{array}{l}\text { Diagnosed } \\
<1 \text { year }\end{array}$ & 2200 & Good \\
\hline$M-4$ & $A B C C 8 \&$ \&CNJ11 & No & No & No & 14 month & 4070 & Good \\
\hline M-7 & $A B C C 8 \& K C N J 11$ & No & IUGR & No & $\begin{array}{l}\text { Diagnosed } \\
<1 \text { year }\end{array}$ & 1900 & Good \\
\hline
\end{tabular}




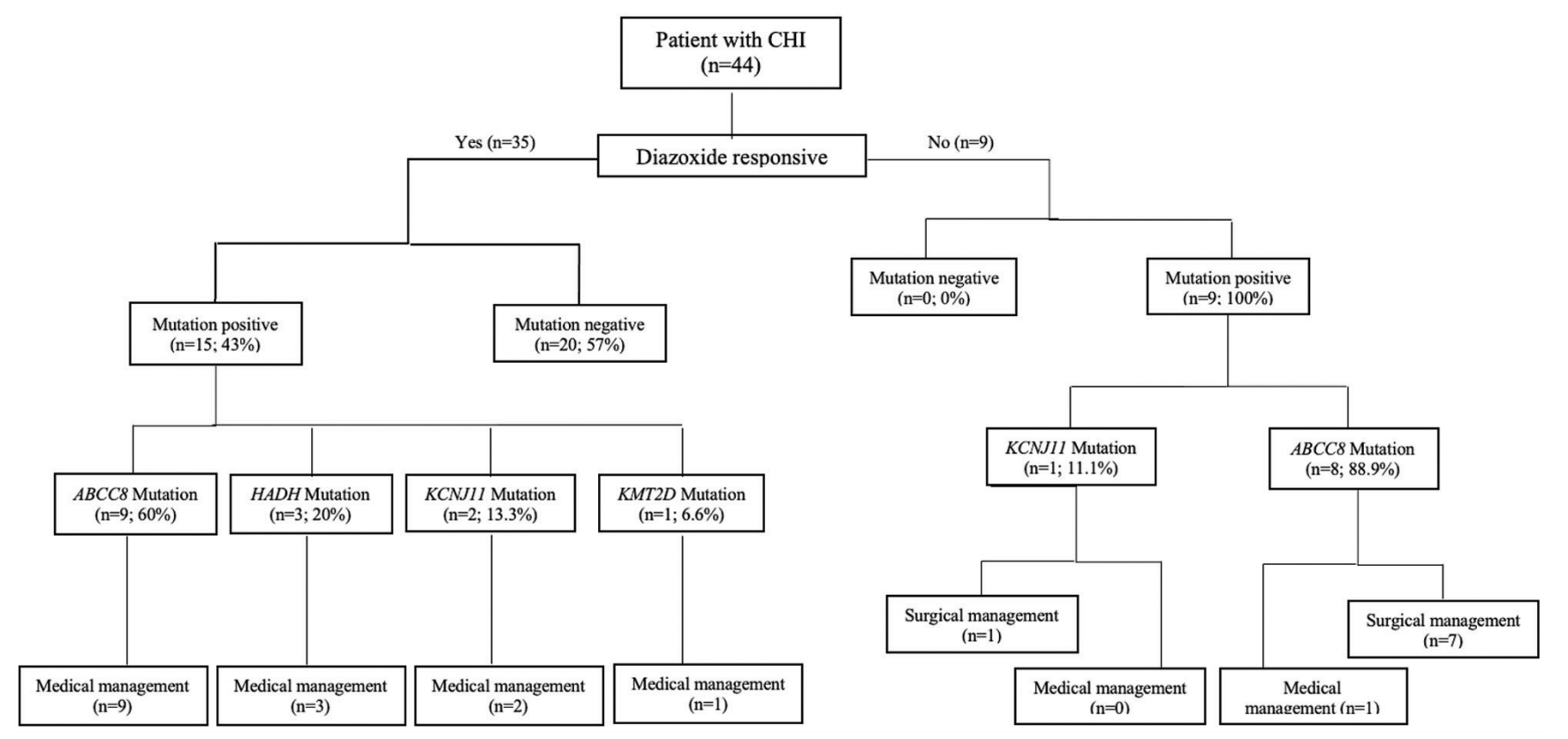

Figure 1. Mutation analysis results and treatment choices for patients with diazoxide-responsive congenital hyperinsulinism (CHI) vs. diazoxide-unresponsive $\mathrm{CHI}$

Although, a subtotal pancreatectomy is necessary in most cases of CHI (24), the vast majority of our participants were diazoxide-responsive $(79 \%)$. Previous studies have reported different rates of diazoxide responsiveness in their cohorts. In studies of de Lonlay et al (8) and Snider et al (17) the ratio of diazoxide-responsive participants were $28 \%$ and $34 \%$, respectively. In a study from Turkey $59 \%$ (13/22) of patients were diazoxide-responsive (10). In 27 infants who were born small-for-gestational age in the UK and developed $\mathrm{HH}$, diazoxide-response was $100 \%$ (25). Diazoxide-responsiveness in two studies of Iranian patients has been reported to be $18 / 23$ and $3 / 6(18,26)$. This discrepancy is probably due to the number of cases in some studies, variable criteria used to define diazoxide responsiveness, differences in sensitivity of the methods used for detecting the mutations and/or occurrence of mutations in combination with a second mutant allele that complicated the prediction of consequences. Our results, however, are consistent with previous studies $(8,27)$, and indicate that $A B C C 8$ gene defects are the most important cause of diazoxide-unresponsive $\mathrm{CHI}$ (8/9 of diazoxide-unresponsive patients) in Iranian children.

The three patients with $H A D H$ homozygous mutations were all diazoxide-responsive. This is consistent with other studies showing hyperinsulinism due to $H A D H$ gene mutations responds relatively well to diazoxide $(12,18,24)$. Mutations in the $H A D H$ gene result in a diffuse form of $\mathrm{CHI}$ (28). Interestingly, the rate of observed $H A D H$ mutations in our study was the same as for KCNJ11 mutations. This result is in concordance with some other studies $(18,26)$. A high frequency of $H A D H$ mutations in our study could be due to a high rate of consanguineous marriage. Based on our results, screening for $H A D H$ gene variants is recommended in all patients with diazoxide-responsive $\mathrm{CHI}$.

One patient in our cohort was mosaic for a KMT2D partial gene deletion. Pathogenic variants in the KMT2D gene cause Kabuki syndrome (29). People with Kabuki syndrome also have facial and some other specific congenital anomalies, including growth delays, mental retardation and skeletal abnormalities, which were not observed in our participant.

In nearly $20 \%$ of patients, no mutation was detected using tNGS, which may miss large deletions and chromosomal rearrangements. Furthermore, negative results do not exclude a monogenic aetiology and further unidentified mutations in other unidentified genes should be considered as new aetiologies.

\section{Study Limitations}

The strength of our study is that we have collected genetic data on the largest cohort of $\mathrm{CHI}$ in an Iranian population to date and identified novel variants causing the disease. Our samples were referred from different parts of Iran. Study limitations include the retrospective collection of clinical data and the lack of follow-up data to assess detailed clinical significance of novel findings. 


\section{Conclusion}

Most novel mutations identified in this study were inherited in a homozygous fashion. Variation in reported rates of diazoxide responsiveness suggest a need for revision of the criteria used to define diazoxide responsiveness. All novel mutations that we report for the first time were medically responsive, and yet should now be considered in $\mathrm{CHI}$ analysis. More studies on the molecular basis of $\mathrm{CHI}$ are necessary for societies with highly consanguineous families. We recommend tNGS for all $\mathrm{CHI}$ patients but screening of $H A D H$ gene variants in patients with diazoxide-responsive $\mathrm{CHI}$ seems to be required if there is no access to tNGS.

\section{Acknowledgments}

We thank all the families and their referring clinicians. The genetic testing, and variant interpretation reported in this paper was performed by the Genomics Laboratory at the University of Exeter, United Kingdom.

\section{Ethics}

Ethics Committee Approval: The study was approved by the Ethical Committee of the Endocrinology and Metabolism Research Institute (ethical code: IR.TUMS. EMRI.REC.1397.009, date: 18.07.2018).

Informed Consent: Informed consent was obtained from parents on behalf of their children.

Peer-review: Externally peer-reviewed.

\section{Authorship Contributions}

Surgical and Medical Practices: Maryam Razzaghy-Azar, Farzaneh Abbasi, Somayyeh Hashemian, Peyman Eshraghi, Siroos Karimdadi, Parisa Tajdini, Rahim Vakili, Concept: Mahsa M. Amoli, Hanieh Yaghootkar, Design: Mahsa M. Amoli, Data Collection or Processing: Sepideh Borhan Dayani, Samaneh Enayati, Analysis or Interpretation: Saeedeh Saeedi, Mahsa M. Amoli, Hanieh Yaghootkar, Literature Search: Saeedeh Saeedi, Mahsa M. Amoli, Writing: Saeedeh Saeedi, Mahsa M. Amoli, Hanieh Yaghootkar.

Financial Disclosure: This work was supported by the Wellcome Trust [108101/Z/15/Z]. H.Y. was funded by Diabetes UK RD Lawrence fellowship (grant: 17/0005594). The genetic testing was performed by the Exeter Genomics Laboratory in the UK with funding from Congenital Hyperinsulinism International (a 501 (c)3 organization).

\section{References}

1. Nestorowicz A, Inagaki N, Gonoi T, Schoor KP, Wilson BA, Glaser B, Landau H, Stanley CA, Thornton PS, Seino S, Permutt MA. A nonsense mutation in the inward rectifier potassium channel gene, Kir6.2, is associated with familial hyperinsulinism. Diabetes 1997;46:1743 1748.

2. Stanley CA, Baker L. The causes of neonatal hypoglycemia. N Engl J Med 1999;340:1200-1201.

3. Mohamed Z, Arya VB, Hussain K. Hyperinsulinaemic hypoglycaemia:genetic mechanisms, diagnosis and management. J Clin Res Pediatr Endocrinol 2012;4:169-181.

4. Demirbilek H, Arya VB, Ozbek MN, Akinci A, Dogan M, Demirel F, Houghton J, Kaba S, Guzel F, Baran RT, Unal S, Tekkes S, Flanagan SE, Ellard S, Hussain K. Clinical characteristics and phenotypegenotype analysis in Turkish patients with congenital hyperinsulinism; predominance of recessive KATP channel mutations. Eur J Endocrinol 2014;170:885-892. Epub 2014 Mar 31

5. Yorifuji T. Congenital hyperinsulinism: current status and future perspectives. Ann Pediatr Endocrinol Metab 2014;19:57-68. Epub 2014 Jun 30

6. Najati N, Saboktakin L. Prevalence and underlying etiologies of neonatal hypoglycemia. Pak J Biol Sci 2010;13:753-756.

7. Mazor-Aronovitch K, Gillis D, Lobel D, Hirsch HJ, Pinhas-Hamiel O, Modan-Moses D, Glaser B, Landau H. Long-term neurodevelopmental outcome in conservatively treated congenital hyperinsulinism. Eur J Endocrinol 2007;157:491-497

8. de Lonlay P, Fournet JC, Touati G, Groos MS, Martin D, Sevin C, Delagne V, Mayaud C, Chigot V, Sempoux C, Brusset MC, Laborde K, BellaneChantelot C, Vassault A, Rahier J, Junien C, Brunelle F, Nihoul-Fékété C, Saudubray JM, Robert JJ. Heterogeneity of persistent hyperinsulinaemic hypoglycaemia. A series of 175 cases. Eur J Pediatr 2002;161:37-48.

9. Stanley CA. Perspective on the Genetics and Diagnosis of Congenital Hyperinsulinism Disorders. J Clin Endocrinol Metab 2016;101:815-826. Epub 2016 Feb 23

10. Guven A, Cebeci AN, Ellard S, Flanagan SE. Clinical and Genetic Characteristics, Management and Long-Term Follow-Up of Turkish Patients with Congenital Hyperinsulinism. J Clin Res Pediatr Endocrinol 2016;8:197-204. Epub 2015 Dec 18

11. Danne T, Nimri R, Battelino T, Bergenstal RM, Close KL, DeVries JH, Garg S, Heinemann L, Hirsch I, A Amiel S, Beck R, Bosi E, Buckingham B, Cobelli C, Dassau E, J Doyle F, Heller S, Hovorka R, Jia W, Jones T, Kordonouri O, Kovatchev B, Kowalski A, Laffel L, Maahs D, R Murphy H, Nørgaard K, G Parkin C, Renard E, Saboo B, Scharf M, V Tamborlane W, A Weinzimer S, Phillip M. International Consensus on Use of Continuous Glucose Monitoring. Diabetes Care 2017;40:1631-1640.

12. Flanagan SE, Patch AM, Locke JM, Akcay T, Simsek E, Alaei M, Yekta Z, Desai M, R Kapoor R, Hussain K, Ellard S. Genome-wide homozygosity analysis reveals HADH mutations as a common cause of diazoxideresponsive hyperinsulinemic-hypoglycemia in consanguineous pedigrees. J Clin Endocrinol Metab 2011;96:E498-502. Epub 2011 Jan 20

13. Xu R, Poole KL, Van Lieshout RJ, Saigal S, Schmidt LA. Shyness and sociability among extremely low birth weight survivors in the third and fourth decades of life: Associations with relationship status. J Pers 2019;87:231-239. Epub 2018 Apr 30

14. James C, Kapoor RR, Ismail D, Hussain K. The genetic basis of congenital hyperinsulinism. J Med Genet 2009;46:289-299. Epub 2009 Mar 1

15. Ellard S, Lango Allen H, De Franco E, Flanagan SE, Hysenaj G, Colclough K, Houghton JAL, Shepherd M, Hattersley AT, Weedon MN, Caswell R. Improved genetic testing for monogenic diabetes using targeted nextgeneration sequencing. Diabetologia 2013;56:1958-1963. Epub 2013 Jun 15

16. Richards S, Aziz N, Bale S, Bick D, Das S, Gastier-Foster J, Grody WW, Hegde M, Lyon E, Spector E, Voelkerding K, Rehm HL, ACMG Laboratory Quality Assurance Committee. Standards and guidelines 
for the interpretation of sequence variants: a joint consensus recommendation of the American College of Medical Genetics and Genomics and the Association for Molecular Pathology. Genet Med 2015;17:405-424. Epub 2015 Mar 5

17. Snider KE, Becker S, Boyajian L, Shyng SL, MacMullen C, Hughes N, Ganapathy K, Bhatti T, Stanley CA, Ganguly A. Genotype and phenotype correlations in 417 children with congenital hyperinsulinism. J Clin Endocrinol Metab 2013;98:E355-E363. Epub 2012 Dec 28

18. Senniappan S, Sadeghizadeh A, Flanagan SE, Ellard S, Hashemipour M, Hosseinzadeh M, Salehi M, Hussain K. Genotype and phenotype correlations in Iranian patients with hyperinsulinaemic hypoglycaemia. BMC Res Notes 2015;8:350

19. Arya VB, Aziz Q, Nessa A, Tinker A, Hussain K. Congenital hyperinsulinism: clinical and molecular characterisation of compound heterozygous $\mathrm{ABCC} 8$ mutation responsive to Diazoxide therapy. Int J Pediatr Endocrinol 2014;2014:24. Epub 2014 Dec 15

20. Nestorowicz A, Glaser B, Wilson BA, Shyng SL, Nichols CG, Stanley CA, Thornton PS, Permutt MA. Genetic heterogeneity in familial hyperinsulinism. Hum Mol Genet 1998;7:1119-1128.

21. Chandran S, Peng FY, Rajadurai VS, Lu YT, Chang KT, Flanagan SE, Ellard S, Hussain K. Paternally inherited ABCC8 mutation causing diffuse congenital hyperinsulinism. Endocrinol Diabetes Metab Case Rep 2013;2013:130041. Epub 2013 Nov 8

22. Hussain K, Flanagan SE, Smith VV, Ashworth M, Day M, Pierro A, Ellard S. An ABCC8 gene mutation and mosaic uniparental isodisomy resulting in atypical diffuse congenital hyperinsulinism. Diabetes 2008;57:259-263. Epub 2007 Oct 17

23. Salomon-Estebanez M, Flanagan SE, Ellard S, Rigby L, Bowden L, Mohamed Z, Nicholson J, Skae M, Hall C, Craigie R, Padidela R, Murphy $\mathrm{N}$, Randell T, E Cosgrove K, J Dunne M, Banerjee I. Conservatively treated Congenital Hyperinsulinism (CHI) due to K-ATP channel gene mutations: reducing severity over time. Orphanet J Rare Dis 2016;11:163

24. Meissner T, Beinbrech B, Mayatepek E. Congenital hyperinsulinism: molecular basis of a heterogeneous disease. Hum Mutat 1999;13:351361.

25. Arya VB, Flanagan SE, Kumaran A, Shield JP, Ellard S, Hussain K, R Kapoor R. Clinical and molecular characterisation of hyperinsulinaemic hypoglycaemia in infants born small-for-gestational age. Archives of disease in childhood Fetal and neonatal edition. Arch Dis Child Fetal Neonatal Ed 2013;98:F356-8. Epub 2013 Jan 29

26. Alaei MR, Akbaroghli S, Keramatipour M, Alaei A. A Case Series: Congenital Hyperinsulinism. Int J Endocrinol Metab 2016;14:e37311. eCollection 2016 Oct

27. Bellanne-Chantelot C, Saint-Martin C, Ribeiro MJ, Vaury C, Verkarre V, Arnoux JB, Valayannopoulos V, Gobrecht S, Sempoux C, Rahier J, Fournet JC, Jaubert F, Aigrain Y, Nihoul-Fékété C, de Lonlay P. ABCC8 and KCNJ11 molecular spectrum of 109 patients with diazoxideunresponsive congenital hyperinsulinism. J Med Genet 2010;47:752759. Epub 2010 Aug 3

28. Clayton PT, Eaton S, Aynsley-Green A, Edginton M, Hussain K, Krywawych S, Datta V, Malingre HE, Berger R, van den Berg IE. Hyperinsulinism in short-chain L-3-hydroxyacyl-CoA dehydrogenase deficiency reveals the importance of beta-oxidation in insulin secretion. J Clin Invest 2001;108:457-465.

29. Ng SB, Bigham AW, Buckingham KJ, Hannibal MC, McMillin MJ, Gildersleeve HI, Beck AE, Tabor HK, Cooper GM, Mefford HC, Lee C, Turner EH, Smith JD, Rieder MJ, Yoshiura K-I, Matsumoto N, Ohta T, Niikawa N, Nickerson DA, Bamshad MJ, Shendure J. Exome sequencing identifies MLL2 mutations as a cause of Kabuki syndrome. Nat Genet 2010;42:790-793. Epub 2010 Aug 15 